\title{
Atypical and dual biotypes variant of virulent SA-NAG-Vibrio cholerae: an evidence of emerging/evolving patho-significant strain in municipal domestic water sources
}

Igere Bright E. ${ }^{1,2^{*}}$, Anthony I. Okoh ${ }^{1,2,3}$ and Uchechukwu U. Nwodo ${ }^{1,2}$

\begin{abstract}
Introduction and purpose: The recent cholera spread, new cases, and fatality continue to arouse concern in public health systems; however, interventions on control is at its peak yet statistics show continuous report. This study characterized atypical and patho-significant environmental Vibrio cholerae retrieved from ground/surface/domestic water in rural-urban-sub-urban locations of Amathole District municipality and Chris Hani District municipality, Eastern Cape Province, South Africa.
\end{abstract}

Methods: Domestic/surface water was sampled and 759 presumptive $V$. cholerae isolates were retrieved using standard microbiological methods. Virulence phenotypic test: toxin co-regulated pili (tcp), choleragen red, protease production, lecithinase production, and lipase test were conducted. Serotyping using polyvalent antisera (Bengal and Ogawa/Inaba/Hikojima) and molecular typing: 16SrRNA, OmpW, serogroup (Vc-O1/O139), biotype (tcpAClas/El Tor, HlyAClas/El Tor, rstRClas/El Tor, RS1, rtxA, rtxC), and virulence ( $c t \times A, c t \times B$, zot, ace, cep, prt, toxR, hlyA) genes were targeted.

Result: Result of 16SrRNA typing confirmed 508 (66.9\%) while OmpW detected/confirmed 61 (12.01\%) V. cholerae strains. Phenotypic-biotyping scheme showed positive test to polymyxin B (68.9\%), Voges proskauer (6.6\%), and Bengal serology (11.5\%). Whereas $\mathrm{Vc}-01 / 0139$ was negative, yet two of the isolates harbored the cholera toxin with a gene-type $c t \times B$ and hlyAClas: 2/61, revealing atypical/unusual/dual biotype phenotypic/genotypic features. Other potential atypical genotypes detected include rstR: 7/61, Cep: 15/61, ace: 20/61, hlyAE/Tor: 53/61, rtxA: 30/61, rtxC: 11/61, and prtv: 15/61 respectively.

Conclusion: Although additional patho-significant/virulent genotypes associated with epidemic/sporadic cholera cases were detected, an advanced, bioinformatics, and post-molecular evaluation is necessary. Such stride possesses potential to adequately minimize future cholera cases associated with dynamic/atypical environmental V. cholerae strains.

Keywords: Cholera, Vibrio cholerae, Phenotypes, Genotypes, Patho-significance, Virulence indices, Unusual/atypical biotype

\footnotetext{
*Correspondence: 201710685@ufh.ac.za; ibe22002@yahoo.com

${ }^{2}$ Applied and Environmental microbiology Research Group (AEMREG),

Department of Biochemistry and Microbiology, University of Fort Hare, Alice, South Africa

Full list of author information is available at the end of the article
}

\section{Introduction}

Cholera, a disease that is associated with dirt, gutter, unhealthy contact with contaminated material and other unhygienic practices has been affirmed to be associated with the pathogen Vibrio cholerae. This organism 
has been classified according to the Bergeys manual of identificative bacteriology among the family Vibrionaceae with more than twelve human and animal pathogenic strains identified. Over the years, there have been reports of sustained implication of the pathogen in acute watery diarrhea, wound infections, otitis media, neonatal meningitis, septicemia, sporadic, and cholera cases (Lu et al. 2014; Marin et al. 2013; Talkington et al. 2011). World Health Organization (WHO) and other investigators in vibriology have affirmed the annual burden of cholera cases to range from 1.3 million to 4.0 million with annual mortality rate ranging from 21,000 to 143,000 worldwide (Ali et al. 2015; WHO facts 2018). Due to their high clinical relevance, they are subdivided into serogroups, serotypes, phage types, and biotype (Momba and Azab El-Liethy 2017). Serogrouping are based on their extracellular polysaccharide into $\mathrm{O} 1, \mathrm{O} 139$, and somatic antigen non-agglutinating $V$. cholerae (SA-NAG-Vibrio cholerae or non-O1/non-O139) (Igbinosa et al. 2009). Biotyping is based on their first place and time of isolation which include Classical, El Tor, Bengal, Calcutta (Mandal et al. 2011). However, two biotypes have been globally distributed and implicated in outbreak reported cases (El Tor and Classical V. cholera). Evident in the early studies was the observation of an El Tor biotype which was first isolated from camp quarantined pilgrims of the El Tor City, located at Sinai Pennisula, Egypt in 1905. According to Zaw et al. (2016) and Mandal et al. (2011), biotyping cholera Vibrio members possess a major epidemiological relevance in the classification scheme of the family Vibrionaceae especially as the pathogen has shown in history, a remarkable disappearance and re-establishment as well as dominance since 1992 (Mandal et al. 2011; Zaw et al. 2016).

Reports from various Vibrio studies have revealed that there exist some new genetic variants of dual biotype with virulent genes suggesting an ongoing evolution as reported by various investigators (Faruque et al. 2007; Goel et al. 2008; Grim et al. 2010; Nair et al. 2006; Zaw et al. 2016). Further results from the study of Ansaruzzaman et al. (2004) in Mozambique, after the cholera outbreak episode in Eastern African countries revealed the presence of an atypical variant of $V$. cholerae with dual biotype and resistant to phage type IV. These reports were affirmed in the studies of Faruque et al. (2007) and Das et al. (2007), who observed two tandem copies of prophage with similar sequence type as $C T X \Phi^{\text {clas }}$ in the pathogen small chromosome. Other investigators of Vibrio have also reported the occurrence of dual phenotype and genotype among pathogenic $V$. cholerae (Ceccarelli et al. 2011; Lee et al. 2009; Nair et al. 2006; Nguyen et al. 2009; Safa et al. 2008; Zaw et al. 2018). Such features are positive and/or negative to chicken red cell agglutination test, Voges Proskauer test, sensitive, and/or resistance to both polymyxin $B$ and phage $V$ but resistance to phage IV (Safa et al. 2010).

Such strains also anchor their genomic composition on two functional but distinct gene clusters, namely, the satellite phage (RS1) and CTX-phi (CTXФ) phage (Castillo et al. 2018; Heidelberg et al. 2000). The classical biotype is shown to possess only the CTXФ, whereas the El Tor biotype possesses both the satellite phage (RS1) and $C T X \Phi$ where $R S 1$ is located adjacent to $C T X \Phi$ as depicted in Fig. 1A, B below (Castillo et al. 2018; Heidelberg et al. 2000; Safa et al. 2010). Present as gene content of $C T X \Phi$ are other two distinct clusters referred to as $R S 2$ and core. The $R S 2$ is also a satellite phage-like particle as the RS1; however, it is similar in genetic content as the RS1 except that it lacks the anti-repressor protein which promotes transcription of CTXФ during the generation and gene expression of infectious particles ( $r s t C$ ) (Banerjee et al. 2014; Safa et al. 2010; Waldor et al. 1997). The core consists of accessory genes needed for secretion and assembling of infectious particles such as CT ( $\operatorname{ctx} A$, $c t x B), p s h, c e p, g^{I I I C T X}, A c e$, and Zot (Fig. 1A). The satellite phage (RS1) consists of rstA gene which is responsible for replication of infectious particles, $r s t B$, which is necessary for integration of viral particles while $r s t R$ and $r s t C$ are necessary for regulation of site specific recombination and gene expression of viral particle, although the $r s t C$ is an anti-repressing protein (Rezaie et al. 2017; Banerjee et al. 2014).

It is important to note that the ctx B gene is present in both the wild-type CTX-phi and the atypical genome. Although the ctx $\mathrm{B}$ gene differs in its amino acid sequences, the CTX-phi gene of the altered/atypical has a notable genome similarity with the Classical CTX-phi genes except for the difference which occurred at rstR. The difference in $c t x B$ genotypes is associated with the global distribution and the wave of evolution over a period of time (Castillo et al. 2018; Banerjee et al. 2014; Safa et al. 2010; Heidelberg et al. 2000). The gene types found in atypical or altered strains of the pathogen are mainly of $R S 1$ and $C T X \Phi$ (RS2 and core) origins which include $r s t A, r s t R, r s t B$, $r s t C$, and CTXФ (cep, ace, zot, rst A, rstB, rstR, psh, $g^{I I-}$ $I C T X, \operatorname{ctx} A, \operatorname{ctx} B)$. Other patho-significant determinants of clinical relevance are $r s t R^{c l a}, r s t R^{E l} T o r, r t x A, r t x C$, and other virulent characteristics (Plaza et al. 2018; Kim et al. 2014; Lee et al. 2009; Nguyen et al. 2009; Safa et al. 2006, 2008; Faruque et al. 2007; Das et al. 2007). The inclusion of the RTX toxin is evident as earlier reported by Heidelberg et al. (2000) in a comparative genomics study which shows that located at the far end of the CTXФ is a region encoding an $R T X$ toxin $(r t x A)$, and its activator $(r t x C)$ with nucleotide 


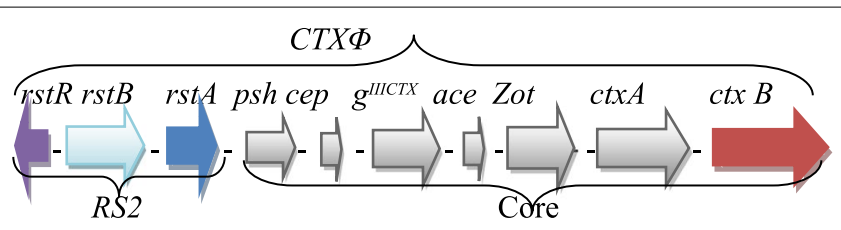

A wide type CTX-phi $(C T X \Phi)$ in all El Tor and Classical $V$. cholerae strains (A)

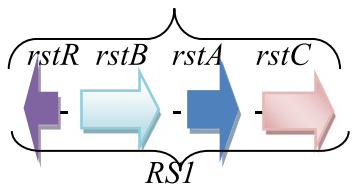

The satellite phage (RS1) and genes in all El Tor $V$. cholerae strains (B)

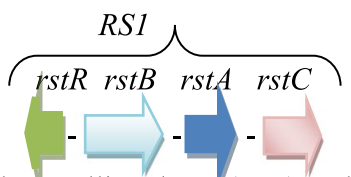

The satellite phage (RS1) and genes in all altered and atypical biotype $V$. cholerae strains $(C)$

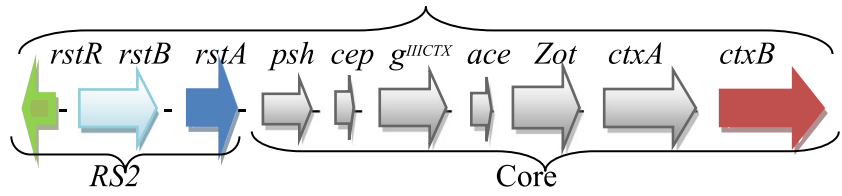

A wide type CTX-phi $(C T X \Phi)$ in Classical/El Tor and altered/atypical $V$. cholerae strains $(D)$

Fig. 1 The genomic composition of the CTX-phi and satellite phage (RS1) in V. cholerae. A wide type CTX-phi (CTXФ) in all El Tor and Classical $V$. cholerae strains (A). The satellite phage (RS1) and genes in all El Tor V. cholerae strains (B). The satellite phage (RS1) and genes in all altered and atypical biotype $V$. cholerae strains (C). A wide type CTX-phi (CTXФ) in Classical/El Tor and altered/atypical V. cholerae strains (D)

composition suggesting the RTX region was horizontally acquired along with other sensor histidine kinase/ response regulator. It also suggests that the regulators affect the expression of some closely related RTX transcriptional units (Castillo et al. 2018; Plaza et al. 2018; $\mathrm{Kim}$ et al. 2014). Atypical strains are rarely reported among environmental SA-NAG- $V$. cholerae strains. In the current study, we confirm atypical/unusual trait/ genes both phenotypically and genotypically among environmental SA-NAG- $V$. cholerae or non-O1/NonO139 $V$. cholerae as evidence of emerging/evolving patho-significant strain in municipal domestic water sources.

\section{Material and methods}

\section{Study area and sample collection}

One liter of domestic water sources was collected onto sterile Nalgene bottles from each of the twenty sampling points which include the waste water treatment plants, receiving water shed, rivers, irrigation canals, dam, and tap water with geographical coordinates as follows: $\mathrm{S} 31^{\circ}$ $54.548^{\prime}$, E $026^{\circ} 50.715^{\prime}$, S $31^{\circ} 54.548^{\prime}$, E $026^{\circ} 50.715^{\prime}, \mathrm{S}$ $31^{\circ} 54.548^{\prime}$, E $026^{\circ} 50.715^{\prime}$, S $31^{\circ} 54.548^{\prime}$, E $026^{\circ} 50.715^{\prime}$. These samples were collected from Amathole District municipality and Chris Hani District municipality of Eastern Cape Province, South Africa. The sampled treatment plant receives municipal wastewater from household/domestic usage and release effluents after treatment into receiving water shed, rivers, dams, and irrigation canal. Such released water is used by the rural population for swine husbandry, irrigation of farm lands, drinking, household/domestic activities, and recreational activities. Most irrigated farm lands with sampled water cultivate and harvest large variety of vegetables both local and commercial farm lands in sub-urban and peri-urban area of study municipalities (Queens Town, Alice). Water samples were collected from treated final effluent before discharge, point of discharge for receiving body of water, $500 \mathrm{~m}$ downstream, and $500 \mathrm{~m}$ upstream of the receiving water discharge point. Samples were collected monthly between February 2018 and August 2018. Specified water samples were collected onto $1 \mathrm{~L}$ screw capped glass Nalgene containers, pre-cleaned/washed using non-ionic detergents and rinsed/bathe in smooth running tap 
water. Additional and further pre-cleaning includes treatment with $5 \%$ concentrate of hydrogen chloride acid and finally with deionized water. Prior to collection of water specimen at various sampling points, $1.7 \mathrm{~mL}$ volume of sterile $1 \%$ sodium thiosulphate solution was added asceptically to specimen bottles. At the collection site/location, midstream water sampling was done by dipping each sterile-secured sample bottle to approximately 20-30 $\mathrm{cm}$ below water surface, projecting the open-mouth of glass bottle or container against water flow direction. Collected samples were thereafter transported in cooler boxes containing ice-packs to the Applied and Environmental Microbiology Research Group (AEMREG) laboratory at the University of Fort Hare, Alice, for respective physicochemical and microbial analyses within 6 to $8 \mathrm{~h}$ after collection.

\section{Physicochemical analysis}

The various sample site geographical coordinates were taken, the distance from analysis laboratory taken, the flow of water into municipality observed, and the wastewater treatment plant capacity design taken. The physicochemical parameters was measured using the following: HANNA HI 96711 free/residual and total chlorine meter for chlorine estimation after pre-preparation with the Merck lovibond DPD-1 tablets; HANNA is a multiple parameter waterproof meter made in Romania Europe (www.hannainst.com). Other machines including $\mathrm{HACH} \mathrm{HQ} 40 \mathrm{D}$ an optimum density meter; $\mathrm{HACH}$ Model CO150 conductivity meter; HACH DR 900 a multiple parameter meter $\mathrm{HACH}$ Company/Hach Lange GmbH, 2013 Model 210A, Orion Laboratories and Life Science membrane filtration system Model No: DOA - P730 - BN, Patr No: 13158 were used to analyze the various physiological properties of the collected water samples on/out site. The study encompasses sampling within three seasons of study area, (Winter, Summer, and Autumn).

\section{Bacterial strains isolation}

Following the previous methods as described by various investigators with few modifications, filtered water samples (vacuum pump/pressure pump: model No. DOA-P730-BN) (www.lasec.co.za) using 0.45- $\mu \mathrm{m}$ nitrocellulose paper (Merck, Germany, www.merck-chemi cals.com) were plated onto pre-prepared Thiosulphate Citrate Bile Salts-Sucrose agar (TCBSA) in triplicate and incubated at $37{ }^{\circ} \mathrm{C}$ for $24 \mathrm{~h}$ (Huq et al. 2012; Igbinosa et al. 2009; Pfeffer and Oliver 2003; Rivera et al. 2013; Uddin et al. 2018). Presumptive yellow and green $V$. cholerae colonies were sub-cultured onto nutrient agar to ascertain the purity subsequently. Three to five colonies per-plate were stored in aliquot on glycerol stock.
Further cultural morphology, colonial morphology, and biochemical characteristics of representative strains were observed/recorded as suspected or presumptive colonies which were subculture onto TCBSA and subsequently onto nutrient agar (NA) to ascertain/confirm purity. These characteristic tests include Gram reaction, oxidase test, motility test, Voges Proskauer test (VP test), and D-mannitol catabolism, while positive strains were selected for confirmation as V. cholera/non-Vibrio strains using serotyping, molecular typing scheme, biotyping serogrouping, and pathotyping as specified by investigators (Beshiru and Igbinosa 2018).

\section{Vibrio numerical density/count}

The method as described by Huq et al. (2012) and Rivera et al. (2013) was employed for isolation with few modifications. Each of the samples was separated into plankton free and plankton associated. Plankton-free samples were filtered after a tenfold dilution treatment using $0.45-\mu \mathrm{m}$ nitrocellulose filter membrane (Merck filter membrane Germany, www.merck-chemicals.com), filtered membrane were plated in triplicate onto thiosulphate citrate bile salts-sucrose agar (TCBSA) and incubated at $37{ }^{\circ} \mathrm{C}$ for $24 \mathrm{~h}$ (Pfeffer and Oliver 2003; Baumann et al. 1984). Plankton-associated samples were pre-treated by centrifuging at $5000 \mathrm{rpm}$ for $1 \mathrm{~min}$ and $1 \mathrm{ml}$ of concentrated homogenates inoculated onto 9-ml sterile Alkaline peptone water (APW). The prepared plankton associated culture was incubated for 6-8 $\mathrm{h}$ and subcultured directly onto thiosulfate citrate bile salt-sucrose agar (TCBSA) and incubating at $37{ }^{\circ} \mathrm{C}$ for $24 \mathrm{~h}$ (Huq et al. 2012; Alam et al. 2006; WHO 2004; Oliver and Kapper 1997).

\section{Presumptive identification, biochemical reaction, and in vitro virulence test}

Pure colonies of presumptive $V$. cholerae isolates were tested using Gram reaction, oxidase reaction, motility and D-mannitol catabolism, Voges-Proskauer, and resistance to polymyxin B. An in vitro presumptive virulence test of isolates was determined using the string test, protease production (protein degrading enzyme test), lipase production (Ryan test or lipid degrading enzyme test), lecithinase production (lecithin degrading enzyme test), and cholera red production (Rivera et al. 2013; Huq et al. 2012; Alam et al. 2006; WHO 2004). Although these determinative tests may not be sufficient for virulence specific identity, they are used as preliminary/presumptive pathotyping procedure for both clinical/environmental $V$. cholerae members. Isolates that reveal positive/ negative reactions to these aforementioned multiple tests were selected presumptively for gene-based confirmation as virulent non-agglutinating $\mathrm{O} 1 / \mathrm{O} 139 \mathrm{~V}$. cholerae members. 


\section{Storage of $V$. cholerae strains}

Yellow and green single colony from a fresh culture were purified and stored in aliquot \{containing 50\% glycerol in $1 \mathrm{ml}$ of sterile Luria Bertani broth on sterile $2 \mathrm{ml}$ graduated skirted-Cryo-preservation tubes (Starlabs, Milton Keynes, UK)\}. The tubes were vortexed briefly to ensure thorough mixing of contents and immediately stored frozen at $-80^{\circ} \mathrm{C}$.

\section{Optimum resuscitation broth (ORB)}

The optimum resuscitation broth \{nutrient broth (Oxoid CM0733)\} was used for preparation of isolate dilutions during water samples collection and isolation of $\mathrm{V}$. cholerae. It was prepared following appropriately the steps on manufacturer's instruction manuals. A $9.5 \mathrm{~g}$ quantity of nutrient broth powder was dissolved in 1 liter of distilled water and sterilized by autoclaving at $15 \mathrm{psi}, 121^{\circ} \mathrm{C}$ for 15 min. Aliquot was stored aseptically at room temperature prior usage.

\section{Phenotypic biotyping of strains}

There are two basic biotypes of $V$. cholerae somatic serogroups, which are Classical and El Tor biotypes. Although a third biotype known as the Bengal biotype appeared as emerging member, it has remained in the Asian continent. The phenotypic biotyping test for isolates was applied using polymyxin B susceptibility, hemolysin test, and Voges-Proskauer test (Forbes et al. 2007).

\section{Polymyxin B (PB) sensitivity}

A modified technique as previously described by Han and Khie (1963) was applied. Mueller-Hinton agar plates were inoculated with standardized saline culture of test organism $\left(4 \mathrm{~h}\right.$ at $\left.35^{\circ} \mathrm{C}\right)$ to obtain confluent growth and then 50 unit $\mathrm{PB}$ antibiotic disk was placed on the surface of medium, was inverted, and was incubated overnight at $37^{\circ} \mathrm{C}$. Classical biotype $V$. cholerae shows a $12-15 \mathrm{~mm}$ zone of inhibition, whereas El Tor Biotype shows complete resistance.

\section{Voges-Proskauer test}

A prepared methyl red and VP reagent was added to pure $24 \mathrm{~h}$ culture of the presumptive isolates. A deep red coloration of medium as the reagent is added to the culture indicates a positive result.

\section{Bengal biotype using serology}

The MAS-AGGL-M15001 Bengal antisera were purchased from the Davis diagnostics \{(Pty) Ltd., 141 Oak Avenue, Ferndale, Randburg, 2194, Gauteng, South Africa (www.daviesdiagnostics.co.za)\}. A single colony from a pure 18-24 h growth culture plate was smeared on a grease-free slide containing two drops of normal saline.
Two drops of Bengal antisera was added and homogenized following manufacturer instructions. Positive report was recorded on observation of agglutination.

\section{Choleragen red}

Alkaline peptone water (APW) [VM 768100 704, Merck KGaA, 64271 Darmstadt, Germany (www.merck-chemi cals.com)] was prepared according to manufacturer's instruction. Pure $24 \mathrm{~h}$ culture of isolates was inoculated onto prepared broth and incubated for $24 \mathrm{~h}$. Few drops of concentrated $\mathrm{H}_{2} \mathrm{SO}_{4}$ were added to the 18-24 h broth culture growth of APW. Positive results were considered when the pale yellow color of APW is turned to pink or pale red.

\section{Molecular typing methods for confirmation DNA extraction}

The boiling method as previously described by Maugeri et al. (2006) was applied. A single colony of the overnight pure culture of presumptive isolate was harvested and/or suspended in ice cold nuclease free 0.5 molar TE \{Tris ethylene diamine tetracetate (EDTA) $\}$ in a $1.5-\mathrm{mL}$ microfuge tube. The tube was heated to boiling using Lasec heating block (www.lasec.co.za) for $10 \mathrm{~min}$ and cooled centrifuged at 15,000 rpm for $8 \mathrm{~min}$ in Eppendorf centrifuge (Hermle Microrifuge; Labortechnik $\mathrm{GmbH}$ Germany). Supernatant of the above preparation was use as bacterial lysate or DNA template during the PCR amplification/detection experiments.

\section{Detection}

All primer sequences were synthesized by Inqaba Biotechnical industries (Pty) Ltd. (www.inqababiotech.co. za). PCR amplification and detection were performed using target specific 16SrRNA primer sequences VF169(5'-GGA TAA CC/TA TTG GAA ACG ATG-3') and VR744-(5'-CAT CTG AGT GTC AGT G/ATC TG3') (617bp) (Yong et al. 2006). The isolates were further confirmed using the $\mathrm{OmpW}$ (304 bp) while other geneticbased elements as well as regions associated with $V$. cholerae virulence, serogroup, and biotype were detected as previously described (see Table S1 below for primer sequence and references). Virulence genes: $\operatorname{ctx} A(\operatorname{ctx} B)$, VSP-II (VC0511, VC0513), VPI-I (tcpA), heat stable enterotoxin (NAG-ST), Zot, ace, cep, prtV, enterotoxigenic hemolysin (hlyA), RTX toxin ( $r t x A) r t x C$, and RS1 were detected. The transcriptional regulator of biotype-specific repeat sequence ( $r s t R), c t x B$ alleles, and $r f b$ gene specific for O1/O139 serogroup genes were also amplified.

\section{PCR amplification}

The amplification was carried out in a $200-\mu l$ microfuge tube. Fifty picomolar to 1 micromolar DNA extract was 
used for the PCR in a final volume of $25 \mu \mathrm{l}$, a GoTaq ${ }^{\circledR} \mathrm{G} 2$ green master mix supplied in $2 \mathrm{X}$ Green $\mathrm{GoTaq}^{\circledR} \mathrm{G} 2 \mathrm{pH}$ : 8.5 reaction solution containing, dNTPs $\{400 \mu \mathrm{M}$ each of dATP, dGTP, dCTP, and dTTP\}, $3 \mathrm{mM} \mathrm{MgCl}_{2}$, and GoTaq $^{\circledR}$ G2 DNA polymerase at optimal concentration for efficient PCR amplification as specified by Promega Corporation USA (www.promega.com). Primer concentration of $0.5 \mu \mathrm{M}$ with the PCR machine (Bio-Rad $\mathrm{T} 100^{\mathrm{TM}}$ thermal cycler) was used. The thermocycling condition were $4 \mathrm{~min}$ at $94{ }^{\circ} \mathrm{C}$ followed by 35 cycles of 94 ${ }^{\circ} \mathrm{C}$ for $1 \mathrm{~min}, 53.0^{\circ} \mathrm{C}$ for $1 \mathrm{~min}$, and $72.0^{\circ} \mathrm{C}$ for $1 \mathrm{~min}$ and a final extension step at $72.0^{\circ} \mathrm{C}$ for $8 \mathrm{~min}$. Other virulent genes cycling conditions are as shown in Table $\mathrm{S} 1$ below.

\section{Tris acetate-EDTA (TAE) or Tris Borate-EDTA (TBE) buffer for gel electrophoresis}

A TAE stock solution was prepared by adding $242 \mathrm{~g}$ of Trizma base, $5.7 \mathrm{ml}$ glacial acetic acid and $100 \mathrm{ml} 0.5 \mathrm{M}$ EDTA (pH: 8.0) into a $1 \mathrm{~L}$ of deionized water to make a 1 $\mathrm{L} 50 \times$ TAE buffer ( $\mathrm{pH}$ 8.0). The working solution consists $20 \mathrm{ml}$ of the stock solution to $980 \mathrm{ml}$ of deionized water (DW) to prepare a $1 \mathrm{~L}$ of $1 \times$ TAE buffer.

\section{Gel electrophoresis}

A small-sized gel was prepared by adding $1.5 \mathrm{~g}$ of agarose (Sigma Aldrich, UK) powder and $100 \mathrm{ml} 1 \times \mathrm{TAE}$ buffer. The mixture was dissolved in a $250-\mathrm{ml}$ conical flask, boiled on a microwave for approximately $3 \mathrm{~min}$ using high heat with intermittent mixing, allowed to cool to about $50{ }^{\circ} \mathrm{C}$ before adding $2 \mu \mathrm{l}$ per $50 \mathrm{ml}$ of ethidium bromide. The gel was casted, allowed to polymerize, transferred onto an electrophoresis tank filled with $1 \times$ TAE buffer to mark. PCR products or amplicons from a thermal cycling process were mixed with loading buffer (bromophenol blue, $0.01 \% \mathrm{w} / \mathrm{v}$, glycerol, $50 \% \mathrm{v} / \mathrm{v}$, EDTA, $0.025 \mathrm{M} \mathrm{pH} \mathrm{8.0)}$ at the ratio of 4:1 (sample:buffer) before loading into the comb wells. The DNA ladder or molecular marker was then loaded without DNA-loading dye. Thereafter, samples were electrophoresed at an appropriate voltage of $100 \mathrm{~V}$ for $50 \mathrm{~min}$ until the dye front was 2 $\mathrm{cm}$ away from the end of the gel. The power was switched off and the electrophoresis tank was disconnected from the power pack. The gel was carefully removed from the casting tray and photograph using the Gel Doc imaging system (Bio Rad, USA).

\section{Statistical analysis}

Pearson correlation was employed to describe and determine level of significances between Vibrio colonial mean cell density/count and the recorded physicochemical parameters in relation to the study sites. This is done to determine the statistical significance of the physicochemical parameters to the proliferation tendency of such emerging strains and/or the Vibrio-colonial density. Such generated data were transferred onto Excel spread sheets to develop tables while other generated data were described using figures.

\section{Results}

The environmental SA-NAG $V$. cholerae strains retrieved was phenotyped and genotyped using microbiological culture dependent methods and PCR. A total of 61 (12.01\%) isolates were PCR confirmed after the detection of 508 (66.9\%) genus specific isolates from 759 presumptive isolates during the study as shown in Fig. 2 and Table 2. The phenotypic character of isolates also further showed that some of them were producer of the cholera toxin as depicted by the choleragen red test (Fig. 3, Table 2). The serological test reveals some of them as Bengal (7/61) serotype, whereas $68.9 \%$ (42) of isolates showed susceptibility to polymyxin B test, while $6.6 \%$ (4) were Voges-Proskauer test positive, protease test [203; (26.8\%)] (Fig. 4; Table 2).

The PCR detection of the CTX-phi, RS 1, RTX cluster, $H L Y-A$ cluster, and the $r s t R$ region of the Classical and El Tor biotype revealed the presence of various genes of emerging relevance. Table S1 shows the various sets of oligonucleotide-primer sequences ranging from genus specific 16SrRNA primer (Yong et al. 2006) to specie specific OmpW gene (Nandi et al. 2000) which confirms the various isolates as $V$. cholerae. The $\operatorname{ctx} A$ gene was not detected during the study whereas $c t x B$ and other toxigenicity associated genes such as $R T X, c e p$, and ace were detected among isolates. All the detected gene markers are located within the CTX-phi, satellite phage, $R T X$ cluster, and the hemolysin A cluster of the classical and El Tor strains of V. cholerae (Safa et al. 2010; Goel and Jiang 2010; Heidelberg et al. 2000; Waldor and Mekalanos 1996). The detection of the RTX toxin (repeat toxin) cluster reveals virulence determinants while $r t x C$ gene detection reconfirm that these isolates where of the $\mathrm{El}$ Tor biotype as previously reported by Chow et al. (2001). The PCR detection of El Tor and the Classical hemolysin gene in $3.27 \%(2 / 61)$ of the isolates analyzed also confirms the occurrence of emerging and unusual genotype among the strains. Further studies are currently ongoing on these atypical $V$. cholerae members in our laboratory and environment which include whole genome sequence analysis, bioinformatics, and phylogenetic study of these members.

From Table 1 above, it was observed that at count $10^{1}$, there was a significant positive correlation between free chlorine $(0.304, \rho<0.05)$; conductivity $(0.418, \rho<0.05)$; specific conductivity $(0.453, \rho<0.05)$; TDS $(0.432, \rho<$ $0.05)$; salinity $(0.357, \rho<0.05)$; temperature $(0.265, \rho<$ $0.05)$; TSS $(0.413, \rho<0.05)$; and TBS $(0.402, \rho<0.05)$ and 


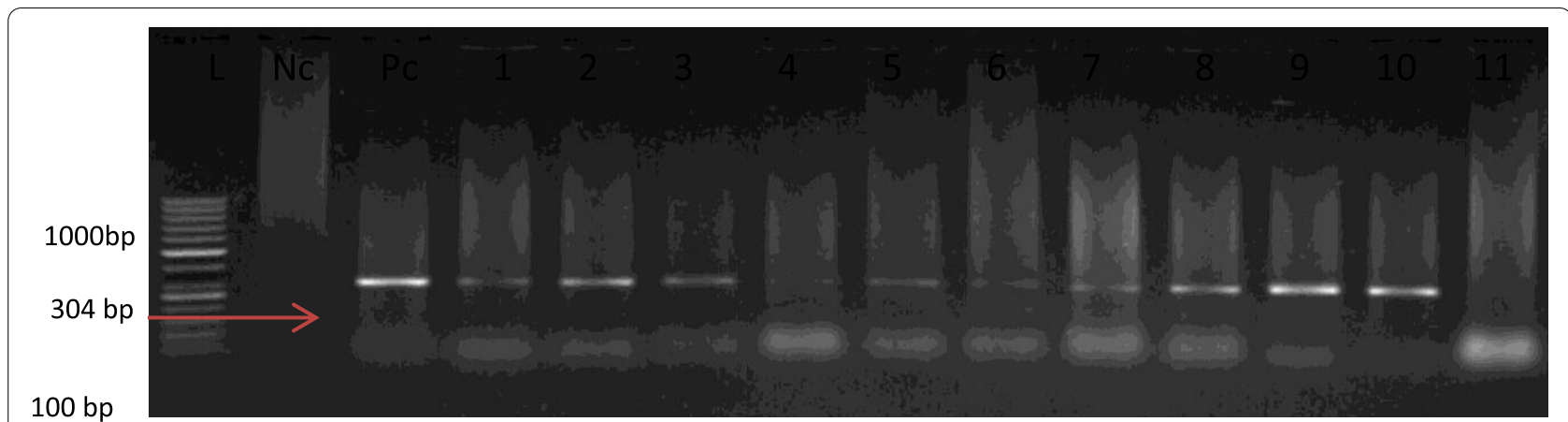

Fig. 2 Electrophoresis photomicrogram OmpW gene detected at $304 \mathrm{bp} L$ represents a molecular marker of $1.2 \mathrm{~kb}$, Pc is a positive control DSM 19130 V. cholerae, Nc is a negative control DSM 8224 Plesiomonas shigelloides, while numbers 1-10 are positive isolates while isolate 11 is negative

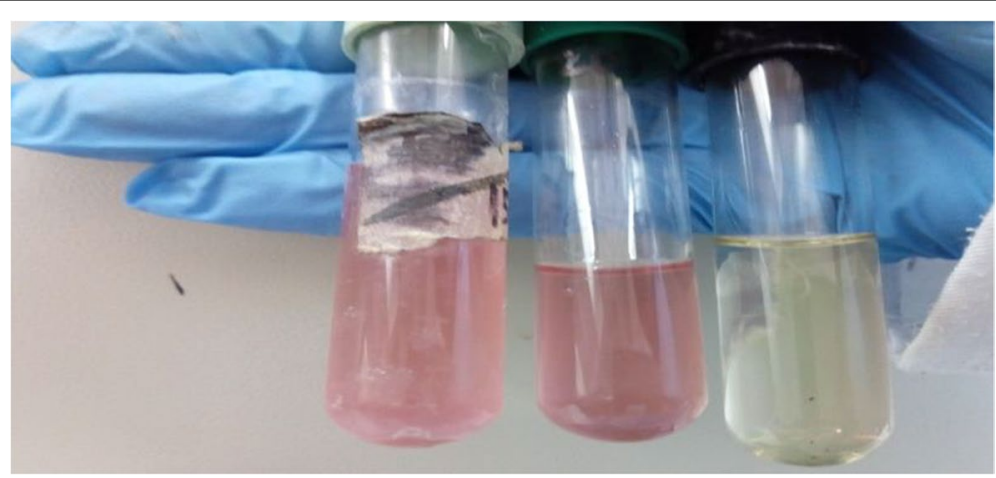

Fig. 3 Choleragen red test for V. cholerae and a negative control DSM 8224 Plesiomonas shigelloides
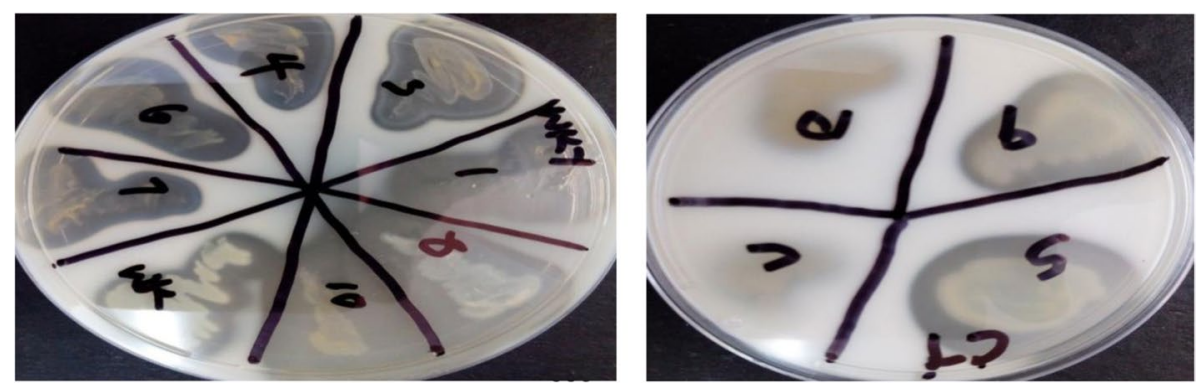

Fig. 4 Protease expression test for V. cholerae and a negative control DSM 8224 Plesiomonas shigelloides

the Vibrio-colonial count. There was also a significant negative correlation between redox potential $(-0.453, \rho<$ $0.05)$; resistivity $(-0.362, \rho<0.05)$; DO $(-0.562, \rho<0.05)$; and DO5 $(-0.557, \rho<0.05)$ with Vibrio-colonial count. The positive significant correlations indicate that as the parameters increases the count at $10^{1}$ increases also significantly. While for the negative significant correlation, as the parameters increases significantly, the count reduces due to anaerobiosis.

It also shows that there was no significant correlation between $\mathrm{mVpH}(-0.054, \rho>0.05)$; $\mathrm{pH}(-0.056, \rho>0.05)$;
Atm pressure $(-0.022, \rho>0.05)$; and BOD $(-0.052, \rho>$ $0.05)$ with Vibrio-colonial count at $10^{1}$. Although there is no significant correlation, the result shows that they were all negatively correlated. This is inferred as follows: as the parameters increases in value, the Vibrio count reduces.

At count $10^{3}$, there was a significant correlation between free chlorine $(0.305, \rho<0.05)$; conductivity (0.268, $\rho<0.05)$; specific count $(0.268, \rho<0.05)$; TDS (0.337, $\rho<0.05)$; salinity $(0.257, \rho<0.05)$; temperature $(0.258, \rho<0.05)$; TSS $(0.409, \rho<0.05)$; and TBS $(0.397, \rho<$ $0.05)$ and Vibrio-colonial counts. There was also negative 
Table 1 Pearson correlation of physio-chemical parameters and Vibrio-colonial counts

\begin{tabular}{|c|c|c|c|c|c|}
\hline \multirow[t]{2}{*}{ Parameters (units) } & \multicolumn{2}{|c|}{ Descriptive statistics } & \multicolumn{3}{|c|}{ Correlation with counts } \\
\hline & $N$ & Mean \pm standard error & $10^{1}$ & $10^{2}$ & $10^{3}$ \\
\hline Free chlorine (mg/L) & 216 & $0.38 \pm 0.49$ & $.304^{* *}$ & $.249^{* *}$ & $.305^{* *}$ \\
\hline $\mathrm{mVpH}$ & 216 & $-29.45 \pm 63.09$ & -.054 & -.021 & .005 \\
\hline $\mathrm{pH}$ & 216 & $7.60 \pm 0.99$ & -.056 & .061 & -.016 \\
\hline Redox potential (mV) & 216 & $49.06 \pm 94.84$ & $-.453^{* *}$ & -.026 & .028 \\
\hline Conductivity ( $\mu \mathrm{S} / \mathrm{cm})$ & 216 & $441.45 \pm 161.22$ & $.418^{* *}$ & $.170^{*}$ & $.268^{* *}$ \\
\hline Specific count ( $\mu \mathrm{S} / \mathrm{cm})$ & 216 & $364.84 \pm 220.90$ & $.453^{* *}$ & $.208^{* *}$ & $.361^{* *}$ \\
\hline Resistivity (m $\Omega . c m)$ & 216 & $0.00 \pm 0.00$ & $-.362^{* *}$ & $-.177^{* *}$ & $-.249 * *$ \\
\hline TDS (mg/LTDS) & 216 & $223.52 \pm 130.84$ & $.432^{* *}$ & $.200^{* *}$ & $.337^{* *}$ \\
\hline Salinity (psu) & 216 & $0.23 \pm 0.15$ & $.357^{* *}$ & $.144^{*}$ & $.257^{* *}$ \\
\hline Temperature $\left({ }^{\circ} \mathbf{C}\right)$ & 216 & $14.03 \pm 4.17$ & $.265^{* *}$ & $.136^{*}$ & $.258^{* *}$ \\
\hline Atm pressure (psi) & 216 & $13.18 \pm 1.61$ & -.022 & .001 & .007 \\
\hline $\mathrm{DO}(\mathrm{mg} / \mathrm{L})$ & 216 & $6.16 \pm 3.49$ & $-.562^{* *}$ & $-.307^{* *}$ & $-.508^{* *}$ \\
\hline DO5 (mg/L) & 216 & $4.32 \pm 3.34$ & $-.557^{* *}$ & $-.317^{* *}$ & $-.442^{* *}$ \\
\hline $\mathrm{BOD}(\mathrm{mg} / \mathrm{L})$ & 216 & $1.80 \pm 1.93$ & -.052 & -.005 & $-.153^{*}$ \\
\hline TSS (mg/L) & 216 & $67.88 \pm 98.52$ & $.413^{* *}$ & $.294^{* *}$ & $.409^{* *}$ \\
\hline TBS (NTU/FAU) & 216 & $75.13 \pm 105.65$ & $.402^{* *}$ & $.292^{* *}$ & $.397^{* *}$ \\
\hline
\end{tabular}

**Sig at 0.01

*Sig at 0.05

Table 2 Density and phenotypic characters of the atypical $V$. cholerae and other members

\begin{tabular}{|c|c|c|c|c|c|c|c|c|}
\hline \multirow[t]{2}{*}{ Sites } & \multirow{2}{*}{$\begin{array}{l}\text { Presumptive } \\
\text { isolates }\end{array}$} & \multirow{2}{*}{$\begin{array}{l}\text { Numbers } \\
\text { confirmed }\end{array}$} & \multirow{2}{*}{$\begin{array}{l}\text { Choleragen red } \\
\text { test }\end{array}$} & \multirow{2}{*}{$\begin{array}{l}\text { Invitro TCP } \\
\text { test }\end{array}$} & \multirow[t]{2}{*}{ String test } & \multicolumn{3}{|c|}{ Phenotypes detected } \\
\hline & & & & & & $\begin{array}{l}\text { Bengal } \\
\text { serotype }\end{array}$ & $\begin{array}{l}\text { Polymyxin B } \\
\text { test }\end{array}$ & $\begin{array}{l}\text { Voges- } \\
\text { Proskauer } \\
\text { test }\end{array}$ \\
\hline WWTP & 327 & 29 & 91 & 27 & 92 & 4 & 27 & 2 \\
\hline RWS & 186 & 15 & 53 & 14 & 51 & 2 & 9 & 1 \\
\hline Rs & 149 & 13 & 27 & 11 & 39 & 1 & 4 & 1 \\
\hline $\mathrm{Ca}$ & 97 & 4 & 8 & 7 & 15 & 0 & 2 & 0 \\
\hline Total & 759 & 61 & 179 & 59 & 197 & 7 & 42 & 4 \\
\hline
\end{tabular}

correlation between resistivity $(-0.249, \rho<0.05)$; DO $(-0.508, \rho<0.05)$; DO5 $(0.442-0.317, \rho<0.05)$; and BOD $(-01.53, \rho<0.05)$ with Vibrio-colonial count, while there was no significant correlation between $\mathrm{mVpH}(0.005, \rho>$ $0.05)$; $\mathrm{pH}(-0.016, \rho>0.05)$; redox potential $(-0.028, \rho>$ $0.05)$, Atm pressure $(-0.007, \rho>0.05)$; and with Vibriocolonial count.

\section{Discussion}

New reports of $V$. cholerae strains continue to surface from diverse region of the world as some reports are associated with the environmental strains. Other reports queried emergence of new strains with high virulent nature necessitating public health interest. The sampled domestic water physico-chemical indices show statistical significance with Vibrio-colonial density/counts (Table 1). This reveals the impact of physicochemical parameters on the proliferating emerging strains. The strains show positive reaction to diverse phenotypic virulent determinants including protease, oxidase, choleragen red test (Figs. 3, 4), and other atypical phenotypes of pathogenic $V$. cholerae as depicted in Table 2 above. The study revealed that $68.9 \%(42 / 61)$ of isolates were susceptible to polymyxin B test, whereas $6.6 \%(4 / 61)$ of isolates were Voges proskauer test positive, while $11.48 \%(7 / 61)$ were positive to the Bengal serological test (Table 2). This implies that the SA-NAG members are emerging with such dual/atypical biotype. This result is similar to the reports of numerous investigators who have observed the dual phenotype 
among V. cholerae (Zaw et al. 2018; Safa et al. 2005, 2006, 2010; Nguyen et al. 2009; Chun et al. 2009; Das et al. 2007; Faruque et al. 2007). Observing variability in susceptibility to polymyxin B by the SA-NAG strains reveals the atypical biotype. It is important to note that the polymyxin sensitivity or resistance has been applied for several decades as an epidemiological bio-marker in the biotyping scheme for $V$. cholerae. This occurrence and other phenotypic virulent indices (Figs. 5, 6,7 , and Table 2) has aroused the need to source track the spread/distribution of the patho-biotype exhibiting emergent trait.

The study also reveals a remarkable occurrence of atypical/unusual genes which are found both in the Classical biotype and the El Tor biotype as previously reviewed by Safa and his colleagues (Safa et al. 2010). The observed genotype/phenotypes were located around the $R S 1$ and CTX $\phi$ regions of either the small and/or large chromosomes (Heidelberg et al. 2000; Safa et al. 2010). According to Faruque and his group, it was reported that these strains with atypical or altered and mixed biotype may have risen from primordial El Tor strains that lost their $C T X \phi^{E l}$ from their large chromosome with a subsequent tandem location of $C T X \phi^{C l a}$ in the small chromosome (Faruque et al. 2007). Nguyen et al. (2009) also reported that these variant biotype strains may possess their $C T X \phi^{\text {Clas }}$ and $C T X \phi^{E l ~ T o r ~}$ either in tandem array or located within two different chromosomes.

It is important to note that previous vibriology investigators studied the $\mathrm{O} 1$ and $\mathrm{O} 139$ pathogenic strains of $V$. cholerae, it appears that the environmental strains (SA-NAG-O1/O139) are currently evolving with related dynamics which calls for prompt survey and/or control measure to avert future difficult to control strain.

Other atypical markers were also observed among our isolates which were similar to those reported recently in the study of Jena et al. (2018) and Samanta et al. (2018), revealing that the occurrence of two biotypes in $V$. cholerae $\mathrm{O} 1$ strain, exhibits diverse pattern of susceptibility to polymyxin B. The result of the PCR detection (Figs. 5, 6, 7) as represented in Table 3 showed that fifteen of the confirmed SA-NAG $V$. cholerae isolates harbored ace (24.6\%) gene, while fourteen harbored cep (23\%) gene. These genes were harbored in the CTX $\phi$ region of the pathogen chromosomes which reveals the presence of the nucleic acid based genotype. In an earlier study of Chun et al. (2009), he referred to strains with the above genotype with the term "a shift or drift between two distinct phyletic lineages" which is seen to be occurring in the environmental SA-NAG strains, and indicates potential evolution/emergence of new

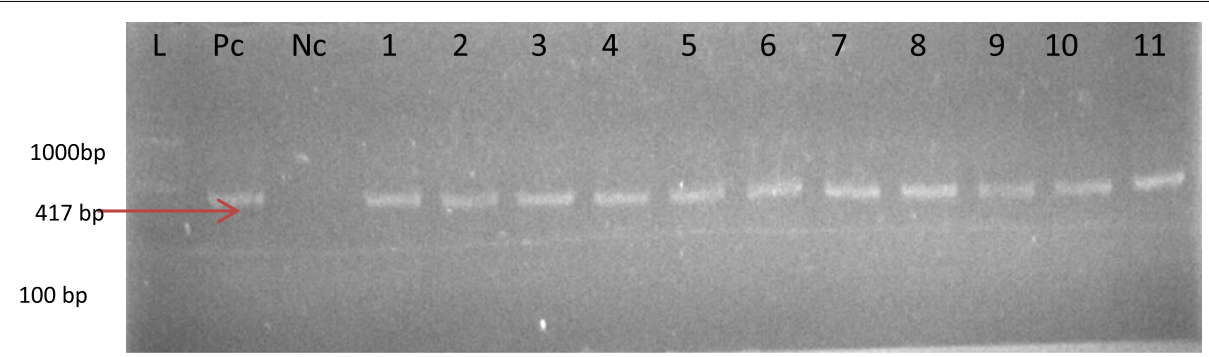

Fig. 5 Electrophoresis photomicrogram rtxA gene detected at 417 bp. L represents a molecular marker of $1.2 \mathrm{~kb}$, Pc is a positive control DSM 19130 $V$. cholerae, $\mathrm{Nc}$ is a negative control DSM 8224 Plesiomonas shigelloides, while numbers 1-11 are positive isolates

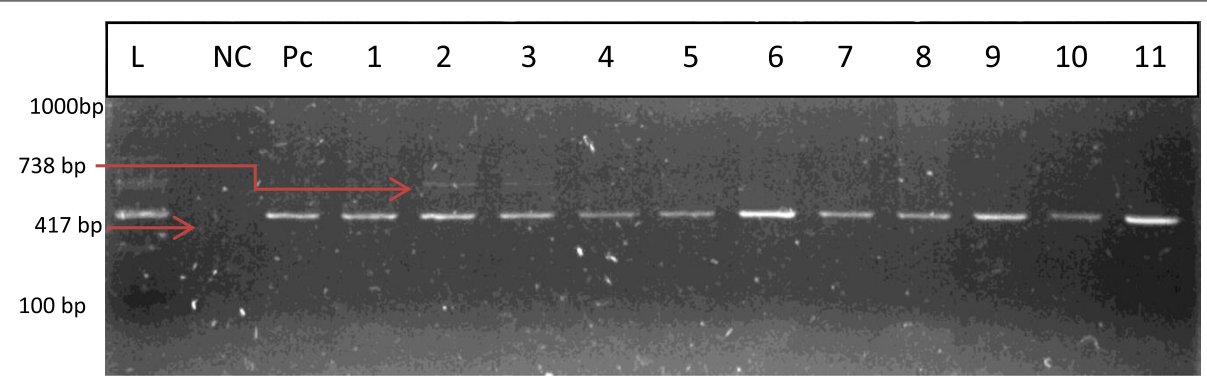

Fig. 6 Electrophoresis potomicrogram hlyA class (738 bp)/El Tor (481 bp) gene detected in atypical strains as depicted in isolate number 2 and 3. $\mathrm{L}$ represents a molecular marker of $1.2 \mathrm{~kb}$, Pc is a positive control DSM $19130 \mathrm{~V}$. cholerae, Nc is a negative control DSM 8224 Plesiomonas shigelloides, while numbers 1-11 are positive isolates for El Tor strains 


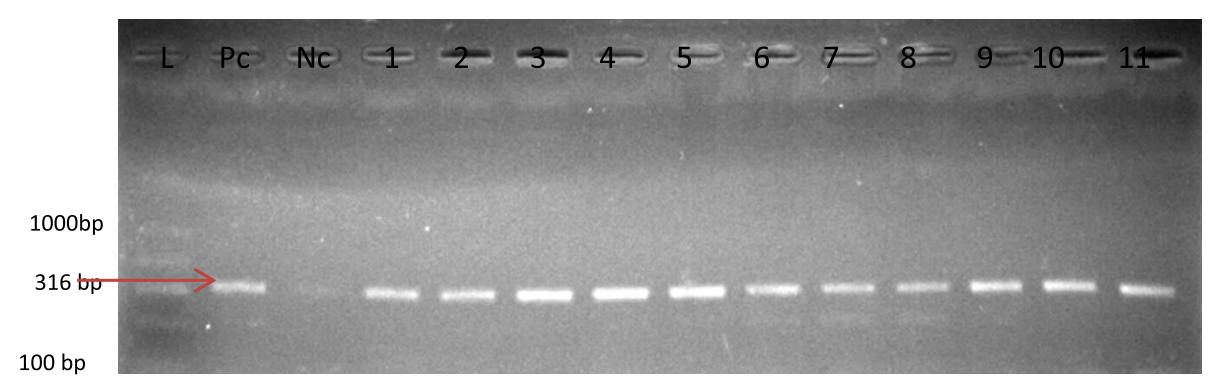

Fig. 7 Electrophoresis photomicrogram ace gene detected at $316 \mathrm{bp}$. L represents a molecular marker of $1.2 \mathrm{~kb}, \mathrm{Pc}$ is a positive control DSM $19130 \mathrm{~V}$. cholerae, Nc is a negative control DSM 8224 Plesiomonas shigelloides, while numbers 1-11 are positive isolates

strains with related pathogenic determinants. Estuarine environment has been shown as $V$. cholerae autochthonous habitat; however, the observation of such atypical or dual biotype strains among environmental $V$. cholerae shows evolving tendency which pose high risk to human and environmental health. Such risk and public health concerns are specifically directed to the urban and sub-urban individuals who use the studied water as their domestic water source. The need for adequate application of hygienic practice and supply of safe water cannot be over emphasized. This observation is also a pointer to the potential occurrence of a transitional representative of genetically identical strains, which possess high virulent potential as the pathogenic strain. It also implies that there is a possibility of an ongoing shift/drift of the environmental strains due to acquisition of new genes over time. Very indicative in the study was the observation of pathogenic emerging indices in somatic antigen non-agglutinating $V$. cholerae strains (SA-NAG-Vc-1/139) which were previously known nonpathogenic $V$. cholerae members.

Among other observed genotypes is an $R T X$ toxigenic gene detected in the RTX cluster which is reported to encode cytotoxic reaction. Tables 3 and 4 show the numbers of isolates with related reports. It is reported to be physically linked to the CTX-phi in the $V$. cholerae genome (Heidelberg et al. 2000; Faruque and Mekalanos
2003) and associated with other residual features in attenuated cholera vaccines. About $49.2 \%$ of the isolates possess $r t x A$ genotype whereas $18 \%$ possess the $r t x C$ genotypes. These observations were also previously reported in the comparative genomics study of Heidelberg et al. (2000) and the characterization of $R T X$ by Chow et al. (2001). It is said that the detection of $R T X$ cluster is associated with actin depolymerisation when cross-linked with Hep-2. Such depolymerisation results villi effacement, hemorrhagic colitis, and bloody diarrhea in infection cases (Chow et al. 2001). This indicates that in any infection case associated with the atypical environmental strains of SA-NAG $V$. cholerae, bloody diarrhea and other symptoms cannot be removed from such cases. The study of Goel and Jiang (2010) also reported a similar occurrence of $R T X(r t x A$ and $r t x C$ ) virulence and cytotoxin genes with such potential clinical symptoms.

Also revealed from this study was the detection of cep gene (23\%) which is associated with the expression of CTX-phi coat protein among strains. This report is similar to the previous annual report of NICED (2004) which indicated that the detection of cep gene is of high and paramount clinical/epidemiological relevance. Cep gene detection may be used instead of $\operatorname{ct} x A$ gene detection while tracking the CTX-phi genes in $V$. cholerae isolates in both outbreak associated location and the environment.

Table 3 Number of confirmed/genotypes detected for atypical V. cholerae and other members

\begin{tabular}{|c|c|c|c|c|c|c|c|c|c|c|c|c|c|}
\hline \multirow[t]{3}{*}{ Sites } & \multirow{3}{*}{$\begin{array}{l}\text { Confirmed } \\
\text { isolates }\end{array}$} & \multicolumn{12}{|c|}{ Genotypes detected } \\
\hline & & \multicolumn{7}{|l|}{$R S 1$} & \multicolumn{5}{|c|}{ CTX-phi } \\
\hline & & $r s t R$ & $r s t A$ & $r s t B$ & $r s t C$ & psh & $g^{I I I C T X}$ & $R S 2$ & cep & ace & Zot & $\operatorname{ctx} A$ & $c t x B$ \\
\hline WWTP & 29 & 4 & ND & ND & 2 & ND & ND & ND & 8 & 11 & 6 & 0 & 2 \\
\hline RWS & 15 & 2 & ND & ND & 0 & ND & ND & ND & 4 & 5 & 5 & 0 & 0 \\
\hline Rs & 13 & 1 & ND & ND & 0 & ND & ND & ND & 2 & 3 & 3 & 0 & 0 \\
\hline $\mathrm{Ca}$ & 4 & 0 & ND & ND & 0 & ND & ND & ND & 1 & 1 & 0 & 0 & 0 \\
\hline Total & 61 & 7 & & & 2 & & & & 15 & 20 & 14 & & 2 \\
\hline
\end{tabular}


Table 4 Numbers of other genotypes detected for atypical $V$. cholerae and other members

\begin{tabular}{|c|c|c|c|c|c|c|c|c|c|}
\hline \multirow[t]{3}{*}{ Sites } & \multirow{3}{*}{$\begin{array}{l}\text { Confirmed } \\
\text { isolates }\end{array}$} & \multicolumn{8}{|c|}{ Other genotypes } \\
\hline & & \multicolumn{2}{|l|}{$R S$} & \multicolumn{2}{|l|}{ HLYA } & \multirow[b]{2}{*}{$\begin{array}{l}\text { Altered/atypical } \\
\text { strains }\end{array}$} & \multicolumn{3}{|l|}{$R T X$} \\
\hline & & rstRclas & rstREI Tor & hlyAclas & hlyAEI Tor & & $r t x A$ & $r t x C$ & prtV \\
\hline WWTP & 29 & 0 & 4 & 2 & 21 & 2 & 13 & 5 & 7 \\
\hline RWS & 15 & 0 & 2 & 0 & 16 & 0 & 8 & 2 & 4 \\
\hline Rs & 13 & 0 & 1 & 0 & 11 & 0 & 7 & 3 & 3 \\
\hline $\mathrm{Ca}$ & 4 & 0 & 0 & 0 & 5 & 0 & 2 & 1 & 1 \\
\hline Total & 61 & Nil & 7 & 2 & 53 & 2 & 30 & 11 & 15 \\
\hline
\end{tabular}

The genotyping analysis of $h l y A$ gene revealed that all isolated $S A-N A G-V c-1 / 139$ strains possessed the El-Tor hemolysin gene which is affirmed to be frequently observed among non-O1/non-O139 V. cholerae (SA-NAG-Vc 1/139) with the exception of two which possess both the Classical and El Tor gene type (Table 4 and Fig. 6). These genotype is said to be unusual among members of the $V$. cholerae family and rare among the non-O1/non-O139 $V$. cholerae strains. The detection of hly $A$ atypical genotype among the nonO1/non-O139 cholera Vibrio members indicates that strains are changing its nature within the environment over time. A previous study by Chatterjee et al. (2009) and Rivera et al. (2001) had reported the presence of the El Tor hemolysin gene (hlyA-El Tor) among non$\mathrm{O} 1$ and non-O139 V. cholerae members; however, the dual phenotype was not observed in their study. Our position remains that the detection of the atypical $V$. cholerae has opened a new area of interest about the potential pathogen in our environmental and domestic water sources.

\section{Conclusion}

A notable report from this study is the observation of biotype gene content as well as other associated genes which are located within the small and large chromosome of the cholera Vibrio. It shows that present in the environment are emerging and evolving strains of SANAG $V$. cholerae which pose threat to the public in the urban and sub-urban area from which these isolates were retrieved. This is used to describe the potential evidence of virulence among environment associated $V$. cholerae (SA-NAG-Vc-1/139) isolated during the study. This study is also necessary as it provide reports of new area of research among $V$. cholerae with specific interest in relevant autochthonous diagnostic scheme, autochthony dependent vaccine design/application and need for other therapeutics. In avoidance of any doubt, more biotype variants with other virulent indices and phenotypic characters may arise in the future which pose futuristic threat to public health. These emerging trend, change, or occurrence necessitate an urgent routine survey with a view to avoiding any looming outbreak. The need for research based and clinical management preparedness for such evolving and emerging strains remains or offers prime hope for possible future management of outbreaks associated with variant and/or altered biotype non-agglutinating $V$. cholerae O1/O139 in various environmental nexus.

\section{Supplementary Information}

The online version contains supplementary material available at https://doi. org/10.1186/s13213-021-01661-5.

Additional file 1: Table S1. The various primer sets, annealing temperature and expected amplicon size

\section{Acknowledgements}

We are grateful to the South African Medical Research Council (SAMRC) and Govan Mbeki Research and Development Centre (GMRDC) of Fort Hare University for their financial support. We will not fail to mention the efforts of Prof Uchechukwu U. Nwodo and Prof A.I Okoh who painstakingly took out time to read through the manuscript, advice, and correct the various phase of the manuscript. We are also grateful to the Biocat subgroup and Aemreg postgraduate students of University of Fort Hare, who willingly donated materials for the study.

\section{Authors' contributions}

IBE: conceptualized, investigated, validate, analysis, data curation, writing original draft, project administration, and editing. AlO: editing, and review the submitted copy. UUN: conceptualization, validation, software, formal analysis, resources, data curation, review/editing, supervision, visualization, and funding acquisition. All authors have read and agreed on the current version.

\section{Authors' information}

Research fellow and investigator at Applied Environmental Microbiology Research Group (AEMREG), Applied and Environmental Microbiology Research Group, and SAMRC Microbial Water Quality Monitoring Centre, University of Fort Hare, Alice, 5700, South Africa.

Bright E. Igere:

A research scientist at the Applied Environmental Microbiology Research Group (AEMREG), Fellow SAMRC Microbial Water Quality Monitoring Centre, University of Fort Hare, Alice, 5700, South Africa. 


\section{Anthony I. Okoh:}

A Professor, Department of Environmental Health Sciences, College of Health Sciences, University of Sharjah, Sharjah, United Arab Emirates. and Department of Biochemistry and Microbiology, University of Fort Hare, Alice, 5700, South Africa.

\section{Uchechukwu U. Nwodo:}

A Professor, Department of Biochemistry and Microbiology, University of Fort Hare, Alice, 5700, South Africa.

\section{Funding}

The authors received no funding from external organisation.

\section{Availability of data and materials}

The datasets as well as results presented in this study are available on request from the corresponding author.

\section{Declarations}

\section{Ethics approval and consent to participate}

There is no identified violation of ethics in this study. The study was conducted to source track and characterizes the emerging indices of environmental and non-01/non-0139 V. cholerae strain which are arising with unusual phenotypic/genotypic biotype features in water nexus. There was no clinically associated specimen hence ethical concerns, consent, and approval were not provided as specimen were environmental basis which was used in executing the study.

\section{Consent for publication}

The authors of this manuscript have read, corrected, and agreed on the final copy reports contained in this study.

\section{Competing interests}

The authors declare that they have no competing interests.

\section{Author details}

${ }^{1}$ Present Address: SAMRC Microbial Water Quality Monitoring Centre ", University of Fort Hare, Alice 5700, South Africa. ${ }^{2}$ Applied and Environmental microbiology Research Group (AEMREG), Department of Biochemistry and Microbiology, University of Fort Hare, Alice, South Africa. ${ }^{3}$ Department of Environmental Health Sciences, College of Health Sciences, University of Sharjah, Sharjah, United Arab Emirates.

Received: 24 August 2021 Accepted: 9 December 2021

Published online: 10 January 2022

\section{References}

Alam M, Hasan NA, Sadique A, Bhuiyan NA, Ahmed KU, Nusrin S, Nair GB, Siddique AK, Sack RB, Sack DA, Huq A (2006) Seasonal cholera caused by Vibrio cholerae serogroups $\mathrm{O} 1$ and $\mathrm{O} 139$ in the coastal aquatic environment of Bangladesh. Appl Environ Microbiol 72(6):4096-4104

Ali M, Nelson AR, Lopez AL, Sack DA (2015) Updated global burden of cholera in endemic countries. PLoS Neg/ Trop Dis 9(6):e0003832. https://doi.org/ 10.1371/journal.pntd.0003832

Alm EW, Oerther DO, Larsen N, Stahl DA, Raskin L (1996) The oligonucleotide probe database. Appl Environ Microbiol 62:3557-3559

Banerjee R, Das B, Nair GB, Basak S (2014) Dynamics in genome evolution of Vibrio cholerae. Infect Genet Evol 23:32-41

Baumann P, Furniss AL, Lee JV (1984) Genus I Vibrio Pacini 1854, 411AL. In Bergey's Manual Systematic Bacteriology, vol 1, pp 518-538. Edited by N. R. Krieg \& J. G. Holt. Baltimore: Williams \& Wilkins

Castillo D, Vandieken V, Engelen B, Engelhardt T, Middelboe M (2018) Draft genome sequences of six Vibrio diazotrophicus strains isolated from deep subsurface sediments of the Baltic sea. Genome Announc 6(10):e00081-e00018

Ceccarelli D, Spagnoletti M, Bacciu D, Cappuccinelli P, Colombo MM (2011) New V. cholerae atypical El Tor variant emerged during the 2006 epidemic outbreak in Angola. BMC Microbiol 11(1):130
Chatterjee S, Ghosh K, Raychoudhuri A, Chowdhury G, Bhattacharya MK, Mukhopadhyay K, Ramamurthy T, Bhattacharya SK, Klose KE, Nandy RK (2009) Incidence, virulence factors, and clonality among clinical strains of non-O1, non-O139 Vibrio cholerae isolates from hospitalized diarrheal patients in Kolkata, India. J Clin Microbiol 47(4):1087-1095

Chow KH, Ng TK, Yuen KY, Yam WC (2001) Detection of RTX toxin gene in Vibrio cholerae by PCR. J Clin Microbiol 39(7):2594-2597

Chowdhury FR, Nur Z, Hassan N, Seidlein L, Dunachie S (2017) Pandemics, pathogenicity and changing molecular epidemiology of cholera in the era of global warming. Ann Clin Microbiol Antimicrob 16(1):10

Chun J, Grim CJ, Hasan NA, Lee JH, Choi SY, Haley BJ, Taviani E, Jeon YS, Kim DW, Lee JH, Brettin TS (2009) Comparative genomics reveals mechanism for short-term and long-term clonal transitions in pandemic Vibrio cholerae. Proc Natl Acad Sci 106(36):15442-15447

Das B, Halder K, Pal P, Bhadra RK (2007) Small chromosomal integration site of classical CTX prophage in Mozambique Vibrio cholerae 01 biotype El Tor strain. Arch Microbiol 188(6):677-683

de Magny GC, Murtugudde R, Sapiano MR, Nizam A, Brown CW, Busalacch AJ, Yunus M, Nair GB, Gil Al, Lanata CF, Calkins J (2008) Environmental signatures associated with cholera epidemics. Proc Natl Acad Sci 105(46):17676-17681

Eibach D, Herrera-León S, Gil H, Hogan B, Ehlkes L, Adjabeng M, Kreuels B, Nagel M, Opare D, Fobil JN, May J (2016) Molecular epidemiology and antibiotic susceptibility of Vibrio cholerae associated with a large cholera outbreak in Ghana in 2014. PLoS Neglect Trop Dis 10(5):e0004751

Faruque SM, Mekalanos JJ (2003) Pathogenicity islands and phages in Vibrio cholerae evolution. Trends Microbiol 11(11):505-510

Faruque SM, Tam VC, Chowdhury N, Diraphat P, Dziejman M, Heidelberg JF, Clemens JD, Mekalanos JJ, Nair GB (2007) Genomic analysis of the Mozambique strain of Vibrio cholerae $\mathrm{O} 1$ reveals the origin of El Tor strains carrying classical CTX prophage. Proc Natl Acad Sci 104(12):5151-5156

Fazil MT, Bhanumathi R, Pandey HP, Singh DV (2011) Characterization of Vibrio cholerae $\mathrm{O} 139$ belonging to multiple ribotypes and isolated from diarrhoeal patients in Kerala, southern India. Infect Genet Evol 11(2):454-459

Forbes BA, Sahm DF, Weissfeld AS (2007) Baily and Scott's diagnostic microbiology (12th Ed.). Mosby Elsevier, pp 62-77 873-890

Goel AK, Jiang SC (2010) Genetic determinants of virulence, antibiogram and altered biotype among the Vibrio cholerae $\mathrm{O} 1$ isolates from different cholera outbreaks in India. Infect Genet Evol 10(6):814-818

Goel AK, Jain M, Kumar P, Bhadauria S, Kmboj DV, Singh L (2008) A new variant of Vibrio cholerae 01 El Tor causing cholera in India. J Infect 57(3):280-281

Grim CJ, Hasan NA, Taviani E, Haley B, Chun J, Brettin TS, Bruce DC, Detter JC, Han CS, Chertkov O, Challacombe J (2010) Genome sequence of hybrid Vibrio cholerae O1 MJ-1236, B-33, and CIRS101 and comparative genomics with V. cholerae. J Bacteriol 192(13):3524-3533

Haley BJ, Chen A, Grim CJ, Clark P, Diaz CM, Taviani E, Hasan NA, Sancomb E, Elnemr WM, Islam MA, Huq A (2012) Vibrio cholerae in a historically cholera-free country. Environ Microbiol Rep 4(4):381-389

Heidelberg JF, Eisen JA, Nelson WC, Clayton RA, Gwinn ML, Dodson RJ, Haft DH, Hickey EK, Peterson JD, Umayam L, Gill SR (2000) DNA sequence of both chromosomes of the cholera pathogen Vibrio cholerae. Nature 406(6795):477

Hoshino K, Yamasaki S, Mukhopadhyay AK, Chakraborty S, Basu A, Bhattacharya SK, Nair GB, Shimada T, Takeda Y (1998) Development and evaluation of a multiplex PCR assay for rapid detection of toxigenic Vibrio cholerae O1 and O139. FEMS Immunol Med Microbiol 20(3):201-207

Huq A, Haley BJ, Taviani E, Chen A, Hasan NA, Colwell RR (2012) Detection, isolation, and identification of Vibrio cholerae from the environment. Curr Prot Microbiol 26(1):6A-65A

Igbinosa EO, Obi LC, Okoh Al (2009) Occurrence of potentially pathogenic vibrios in final effluents of a wastewater treatment facility in a rural community of the Eastern Cape Province of South Africa. Res Microbiol 160(8):531-537

Jena PP, Gur R, Sharma A, Duggal SD, Bharara T (2018) Antibiotic susceptibility profile of 'Vibrio Cholerae O1 Biotype El Tor Serotype Ogawa' outbreak in North Delhi, India. Journal of Pediatric Infectious Diseases

Kaper JB, Morris JG Jr, Levine MM (1995) Cholera. Clin Microbiol Rev 8:48-86 
Khan IA, Saha A, Chowdhury F, Khan Al, Uddin MJ, Begum YA, Riaz BK, Islam S, Ali M, Luby SP, Clemens JD (2013) Coverage and cost of a large oral cholera vaccination program in a high-risk cholera endemic urban population in Dhaka, Bangladesh. Vaccine 31(51):6058-6064

Kim EJ, Lee D, Moon SH, Lee CH, Kim DW (2014) CTX prophages in Vibrio cholerae $\mathrm{O} 1$ strains. J Microbiol Biotechnol 24(6):725-731

Lee JH, Choi SY, Jeon YS, Lee HR, Kim EJ, Nguyen BM, Hien NT, Ansaruzzaman M, Islam MS, Bhuiyan NA, Niyogi SK (2009) Classification of hybrid and altered Vibrio cholerae strains by CTX prophage and RS1 element structure. J Microbio/ 47(6):783-788

Lu B, Zhou H, Li D, Li F, Zhu F, Cui Y, Huang L, Wang D (2014) The first case of bacteraemia due to non-O1/non-O139 Vibrio cholerae in a type 2 diabetes mellitus patient in mainland China. Int J Infect Dis 25:116-118

Mandal S, Mandal MD, Pal NK (2011) Cholera: a great global concern. Asian Pac J Trop Med 4(7):573-580

Marin MA, Thompson CC, Freitas FS, Fonseca EL, Aboderin AO, Zailani SB, Quartey NKE, Okeke IN, Vicente ACP (2013) Cholera outbreaks in Nigeria are associated with multidrug resistant atypical El Tor and non-O1/non-0139 Vibrio cholerae. PLoS Neglected Tropical Diseases 7(2):e2049

Maugeri TL, Carbone M, Fera MT, Gugliandolo C (2006) Detection and differentiation of Vibrio vulnificus in seawater and plankton of a coastal zone of the Mediterranean Sea. Res Microbiol 157(2):194-200

Nair GB, Faruque SM, Bhuiyan NA, Kamruzzaman M, Siddique AK, Sack DA (2002) New variants of Vibrio cholerae O1 biotype El Tor with attributes of the classical biotype from hospitalized patients with acute diarrhea in Bangladesh. J Clin Microbiol 40(9):3296-3299

Nair GB, Qadri F, Holmgren J, Svennerholm AM, Safa A, Bhuiyan NA, Ahmad QS, Faruque SM, Faruque ASG, Takeda Y, Sack DA (2006) Cholera due to altered El Tor strains of Vibrio cholerae $\mathrm{O} 1$ in Bangladesh. J Clin Microbiol 44(11):4211-4213

Nandi B, Nandy RK, Mukhopadhyay S, Nair GB, Shimada T, Ghose AC (2000) Rapid method for species-specific identification of Vibrio cholerae using primers targeted to the gene of outer membrane protein OmpW. J Clin Microbiol 38(11):4145-4151

Nguyen BM, Lee JH, Cuong NT, Choi SY, Hien NT, Anh DD, Lee HR, Ansaruzzaman M, Endtz HP, Chun J, Lopez AL (2009) Cholera outbreaks caused by an altered Vibrio cholerae O1 El Tor biotype strain producing classical cholera toxin B in Vietnam in 2007 to 2008. J Clin Microbiol 47(5):1568-1571

O'Shea, Y.A., Finnan, S., Reen, F.J., Morrissey, J.P., O'Gara, F. and Boyd, E.F., (2004). The Vibrio seventh pandemic island-II is a $26.9 \mathrm{~kb}$ genomic island present in Vibrio cholerae El Tor and 0139 serogroup isolates that shows homology to a $43.4 \mathrm{~kb}$ genomic island in V. vulnificus. Microbiology, 150(12), pp.4053-4063.

Oliver J D, Kapper JB(1997) Vibrio species. In: Food Microbiology: Fundamentals and Frontiers.eds M. P.; Doyl, L. R. Beuchat, and T. J Montville, pp 228-260 ASM press, Washington D C., USA

Patra T, Chatterjee S, Raychoudhuri A, Mukhopadhyay AK, Ramamurthy T, Nandy RK (2011) Emergence and progression of Vibrio cholerae O1 El Tor variants and progenitor strains of Mozambique variants in Kolkata, India. Int J Med Microbio/ 301(4):310-317

Pfeffer C, Oliver JD (2003) A comparison of thiosulphate-citrate-bile saltssucrose (TCBS) agar and thiosulphate-chloride-iodide (TCI) agar for the isolation of Vibrio species from estuarine environments. Lett Appl Microbio/ 36(3):150-151

Plaza N, Castillo D, Pérez-Reytor D, Higuera G, García K, Bastías R (2018) Bacteriophages in the control of pathogenic vibrios. Electron J Biotechnol 31:24-33

Rezaie N, Bakhshi B, Najar-Peerayeh S (2017) The role of CTX and RS1 satellite phages genomic arrangement in Vibrio cholera toxin production in two recent cholera outbreaks (2012 and 2013) in IR Iran. Microb Pathog 112:89-94

Rivera ING, Chun J, Huq A, Sack RB, Colwell RR (2001) Genotypes associated with virulence in environmental isolates of Vibrio cholerae. Appl Environ Microbiol 67(6):2421-2429

Rivera FP, Medina AM, Bezada S, Valencia R, Bernal M, Meza R, Maves RC, Ochoa TJ (2013) Bovine lactoferrin decreases cholera-toxin-induced intestinal fluid accumulation in mice by ganglioside interaction. PloS One 8(4):e59253

Safa A, Bhuiyan NA, Alam M, Sack DA, Nair GB (2005) Genomic relatedness of the new Matlab variants of Vibrio cholerae $\mathrm{O} 1$ to the classical and $\mathrm{E}$
Tor biotypes as determined by pulsed-field gel electrophoresis. $J$ Clin Microbiol 43(3):1401-1404

Safa A, Bhuyian NA, Nusrin S, Ansaruzzaman M, Alam M, Hamabata T, Takeda Y, Sack DA, Nair GB (2006) Genetic characteristics of Matlab variants of Vibrio cholerae $\mathrm{O} 1$ that are hybrids between classical and El Tor biotypes. J Med Microbiol 55(11):1563-1569

Safa A, Sultana J, Cam PD, Mwansa JC, Kong RY (2008) Vibrio cholerae O1 hybrid EI Tor strains, Asia and Africa. Emerg Infect Dis 14(6):987-988

Safa A, Bhuiyan NA, Murphy D, Bates J, Nusrin S, Kong RY, Chongsanguan M, Chaicumpa W, Nair GB (2009) Multilocus genetic analysis reveals that the Australian strains of Vibrio cholerae $\mathrm{O} 1$ are similar to the pre-seventh pandemic strains of the El Tor biotype. J Med Microbio/ 58(1):105-111

Safa A, Nair GB, Kong RY (2010) Evolution of new variants of Vibrio cholerae O1. Trends Microbiol 18(1):46-54

Samanta P, Saha RN, Chowdhury G, Naha A, Sarkar S, Dutta S, Nandy RK, Okamoto K, Mukhopadhyay AK (2018) Dissemination of newly emerged polymyxin B sensitive Vibrio cholerae O1 containing Haitian-like genetic traits in different parts of India. J Med Microbiol

Shimada T, Arakawa E, Itoh K, Okitsu T, Matsushima A, Asai Y, Yamai S, Nakazato T, Nair GB, Albert MJ, Takeda Y (1994) Extended serotyping scheme forVibrio cholerae. Curr Microbiol 28(3):175-178

Singh DV, Matte MH, Matte GR, Jiang S, Sabeena F, Shukla BN, Sanyal SC, Huq A, Colwell RR (2001) Molecular analysis of Vibrio choleraeO1, O139, non-O1, and non-O139 strains: clonal relationships between clinical and environmental isolates. App/ Environ Microbiol 67(2):910-921

Syahril NA, Mariana NS, Sidhu HS, Rosil R (2002) In vitro expression of the ctxB toxin gene towards the development of a DNA vaccine against cholera. Mol Biol Today 3(3):71-77

Talkington D, Bopp C, Tarr C, Parsons MB, Dahourou G, Freeman M, Joyce K, Turnsek M, Garrett N, Humphrys M, Gomez G (2011) Characterization of toxigenic Vibrio cholerae from Haiti, 2010-2011. Emerg Infect Dis 17(11):2122

Taneja N, Sangar G, Chowdhury G, Ramamurthy T, Mishra A, Singh M, Sharma M (2012) Molecular epidemiology of Vibrio cholerae causing outbreaks \& sporadic cholera in northern India. Indian J Med Res 136(4):656

Thompson FL, lida T, Swings J (2004) Biodiversity of vibrios. Microbiol Mol Biol Rev 68:403-431

Uma G, Chandrasekaran M, Takeda Y, Nair GB (2003) Recent advances in cholera genetics. Cur Sci:1538-1545

Waldor MK, Mekalanos JJ (1996) Lysogenic conversion by a filamentous phage encoding cholera toxin. Science 272(5270):1910-1914

Waldor MK, Rubin EJ, Pearson GD, Kimsey H, Mekalanos JJ (1997) Regulation, replication, and integration functions of the Vibrio cholerae CTXФ are encoded by region RS2. Mol Microbiol 24(5):917-926

WHO (2004) Water, sanitation and hygiene links to health: facts and figures, Geneva

WHO (2017) Guidance on regulations for the transport of infectious substances 2017-2018. http://apps.who.int/iris/bitstream/10665/254788/1/ WHO-WHE-CPI-2017.8-eng.pdf?ua=1

World Health Organization (2018) Fourth annual meeting of the Global Task Force on Cholera Control: 21-22 June 2017, Cape Town, South Africa (No. WHO/WHE/IHM/EMI/2018.2). World Health Organization

Yong L, Guanpin Y, Hualei W, Jixiang C, Xianming S, Guiwei Z, Qiwei W, Xiuqin S (2006) Design ofVibrio 165 rRNA gene specific primers and their application in the analysis of seawater Vibrio community. J Ocean Univ China 5(2):157-164

Zaw MT, Emran NA, Naing DKS, Lin Z (2016) Atypical El Tor: new Vibrio cholerae O1 biotype causing epidemic cholera. Borneo J Med Sci (BJMS) 10

Zaw MT, Emran NA, Ibrahim MY, Suleiman M, Mohd TAA, Yusuff AS, Naing KS, Myint T, Jikal M, Salleh MA, Lin Z (2018) Genetic diversity of toxigenic Vibrio cholerae O1 from Sabah, Malaysia 2015. J Microbiol Immunol Infect

\section{Publisher's Note}

Springer Nature remains neutral with regard to jurisdictional claims in published maps and institutional affiliations. 